\title{
A fome e outras mazelas vividas no romance Ponciá Vicêncio, de Conceição Evaristo
}

\section{The hunger and other ills experienced in the novel Ponciá Vicêncio, by Conceição Evaristo}

\author{
Denise Aparecida do Nascimento* \\ Universidade Estadual da Paraíba \\ Campina Grande, Paraíba, Brasil
}

\begin{abstract}
Resumo: O presente artigo pretende refletir a severa denúncia de exclusão social vivenciado, principalmente, pelos negros ou afro-brasileiros dos grandes centros. Para tanto, consideramos o romance Ponciá Vicêncio (2003), de Conceição Evaristo, visto que no romance em questão a autora aponta a fome, a depressão e a melancolia como consequências da opressão social.
\end{abstract}

Palavras-chave: Fome; Depressão; Denúncia Social.

\begin{abstract}
This article intends to reflect the severe denunciation of social exclusion experienced mainly by black peoples or afro-brazilian of the major centres. Thus, we consider the novel Ponciá Vincencio (2003), of Conceição Evaristo, since in the novel in question the author points to hunger, depression and melancholy as consequences of social oppression.
\end{abstract}

Keywords: Hunger; Depression; Social Complaint.

\section{INTRODUÇÃO}

Dos flagelos reinantes no mundo atual, talvez o pior deles seja a fome. Embora o artigo $1^{\circ}$ da Declaração Universal dos Direitos Humanos garanta que: "Todos os seres humanos nascem livres e iguais em dignidade e em direitos. Dotados de razãa e de consciência, devem agir uns para com os outros em espírito de fraternidade", na realidade não é o que sempre acontece. Grande parte da população mundial vive a escassez de alimentos. Em 1945 os Estados tomaram consciência das atrocidades vividas e deixadas pela $2^{a}$ G.G. e decidiram formar uma organização que tinha como função precípua preservar as futuras gerações do flagelo da guerra e, consequentemente, seus rastros. A criação da ONU simboliza a necessidade de se cultivar a tolerância, a paz, e a solidariedade entre as nações (ONUBR, 2018); diante desta expectativa torna-se inaceitável conceber que em um mundo de avanços tecnológicos e de abundância, a fome esteja ainda presente na vida de milhões de pessoa em tantos países.

No Brasil, uma das grandes mazelas da sociedade reside exatamente na existência de um importante contingente de pessoas que não tem acesso à alimentação adequada, passando por sérias dificuldades, deixando marcas profundas em parte da população infantil que carregará para o resto da vida sequelas de uma primeira infância destruída pela fome. $\mathrm{Na}$ realidade brasileira a

* Doutora em Letras pela Universidade Federal de Juiz de Fora. E-mail: denablue72@gmail.com 
fome se apresenta travestida em outras carências que vão desde um sistema de saúde precário, passando por sistemas educacionais, de transporte e segurança pública defasada; enfim, a fome no Brasil deve ser compreendida em sentido amplo.

\section{A FOME NA LITERATURA}

As artes levam-nos à dimensão estética da existência (...). Trata-se enfim, de demonstrar que, em toda grande obra, de literatura, de cinema, de poesia, de música, de pintura, de escultura, há um pensamento profundo sobre a condição humana. (MORIN, 2006, p. 45)

A condição humana é temática nas variadas formas de expressões artísticas desde os primórdios da humanidade. Os registros rupestres encontrados ao redor do mundo confirmam esse fato.

Nessa perspectiva, o fenômeno da fome retrata uma das agruras que mais assombra o homem, diante dos possíveis símbolos que pode representar. Em outras palavras, diante da situação de fome, o homem se torna capaz de realizar atos bestiais e indignos de um ser pensante. Conforme a epígrafe supracitada, a literatura pode também se encarregar de denunciar as feridas e agruras que perpassam grande parcela da população mundial.

$\mathrm{Na}$ Literatura Brasileira há grandes romances que retratam o fenômeno da fome, tais como nas obras, Vidas Secas (1938) de Graciliano Ramos, O Quinze (1930) de Rachel de Queiroz e A Fome (1890), do quase desconhecido Rodolfo Teófilo. Em comum, além da temática abordada, todos localizam a fome nordestina especificamente, uma vez que falam do flagelo na região nordeste do Brasil.

Isto posto, o texto aqui apresentado busca refletir sobre a condição da população negra no Brasil e de como o fenômeno da fome é tratado na literatura afro-brasileira. Vale lembrar que um livro considerado por muitos críticos e leitores como inaugural em desvelar a realidade dessa parcela da população brasileira é Quarto de despejo: diário de uma favelada (1960), da escritora negra, brasileira e favelada, Carolina Maria de Jesus.

No livro, a escritora relata o cotidiano de fome que enfrentava com seus três filhos na favela do Canindé, em São Paulo na década de 1950. Dessa forma, deu início a um formato de narrativadenúncia, em que revela o abismo social que dividia um Brasil até então ignorado por muitos brasileiros. Denúncias tais como as passagens seguintes ${ }^{1}$, extraídas do livro, em que a escritora expressa sua consciência política aguçada, apesar de sua pouca instrução: " 6 de maio (...) O que eu aviso aos pretendentes a política, é que o povo não tolera a fome. É preciso conhecer a fome para saber descrevê-la." (JESUS, 1960, p. 26). Ou ainda quando expõe os efeitos da fome: "27 de maio: (...). A tontura da fome é pior do que a do álcool. A tontura do álcool nos impele a cantar. Mas a da fome nos faz tremer. Percebi que é horrível ter só ar dentro do estômago." (JESUS, 1960 , p. 39).

\footnotetext{
${ }^{1}$ Respeitaremos aqui a escrita da autora, conforme extraída do texto.
} 
O livro é atemporal, pois como já dito, tornou-se referência quando a discussão é sobre a realidade e as mazelas do sujeito favelado. Ressalta-se também a relevância da presença de Carolina Maria de Jesus, quando a abordagem é sobre a escrita negra e feminina.

Em se tratando de literatura afro-brasileira, cabe salientar que na atualidade, ao mesmo tempo em que se comemoram várias realizações e descobertas, a mesma continua causando divergências - alguns críticos não a legitimam outros a consideram como "uma literatura em construção" - Segundo Eduardo Duarte (s/d) a consolidação de uma literatura "afrobrasileira" passa pela noção de uma identidade una e coesa, e que em virtude de um número ainda insuficiente de estudos, debates, fóruns específicos e pesquisa a respeito, assim como a ausência da disciplina "Literatura Afrobrasileira" nos currículos de graduação e pós-graduação da maioria dos cursos de Letras no Brasil, contribuem para a pouca informação sobre esta literatura. Nessa perspectiva, percebe - se o romance Ponciá Vicêncio (2003), da escritora Conceição Evaristo como aquela escrita que se acomoda no lugar "supostamente" vago da literatura afro-brasileira.

\section{FOME, MELANCOLIA E DEPRESSÃO}

A escrita de Conceição Evaristo se constrói a partir de sua realidade e identidade como mulher negra, trazendo as marcas de uma história pessoal, em uma linguagem particular que nos remete à memória de um povo que cruzou o Atlântico e se perdeu na história. A escritora (re)escreve essa história e expõe as dores desse povo utilizando os sentidos da palavra Banzo.

$\mathrm{Na}$ época do tráfico negreiro, muitos negros que chegaram aqui no Brasil não suportaram a saudade, a falta dos seus e todas suas perdas; muitos morreram ainda na travessia devido aos maus tratos, outros provocaram a própria morte se recusando a comer ou beber, morriam de inanição. Diziam sofrer de banzo ou de uma tristeza profunda.

O Dicionário Aurélio (2010), define Banzo como: "Nostalgia mortal que atacava os negros escravizados e retirados da África". Para a definição de depressão, o dicionário aponta: "um estado patológico de sofrimento psíquico assinalado por um abaixamento do sentimento de valor pessoal, por pessimismo e por uma inapetência face à vida"; e para melancolia a definição é: "um estado psíquico de depressão sem causa específica”.

Alguns estudiosos defendem que a escrita negra esteja permeada por esses sentimentos, mas que tal escrita não pode ser reduzida a simples registros de tristezas. Para a escritora Conceição Evaristo o termo "banzo", assim como seu sentido não pode definir a escrita negra, mas deve ser recuperado e potencializado em suas produções.

No romance Ponciá Vicêncio, Evaristo propõe a imagem de uma mulher melancólica e não generalizada como aquelas construídas em romances, em sua maioria escritos por homens como sensuais, promíscuas, fogosas, objetos sexuais. A partir dessa perspectiva, é possível enxergar a experiência feminina negra sobre outra ótica que não a da eterna submissão ou de um otimismo exarcebado que chega a encobrir uma condição "natural" para a subalternidade.

Ponciá Vicêncio é um romance de ficção sobre uma mulher negra e sua família. O livro é narrado em dois tempos que se mesclam; o presente é entrecortado pelo passado em vários flashbacks. Ponciá Vicêncio, personagem-título do romance nos é apresentada sempre em dois 
momentos: Ponciá-menina e Ponciá-mulher. Ambas guardam em comum a busca pela identidade, pois desde pequena a menina não reconhecia o próprio sobrenome: Vicêncio. $\mathrm{O}$ nome que designava todos de sua família e da vila. Todos eram propriedades do Coronel Vicêncio; todos eram heranças da escravidão.

Ponciá Vicêncio sabia que o sobrenome dela tinha vindo desde antes do avô de seu avô (...). O pai, a mãe, todos continuavam Vicêncio. Na assinatura dela, a reminiscência do poderio do senhor, de um tal de coronel Vicêncio...(EVARISTO, 2003, p. 27).

Ponciá projetava para si aquele que seria um caminho natural a seguir, teria um marido, teria filhos, teria uma casa em que reinaria como uma rainha, assim como a mãe. Ambas viviam praticamente sozinhas, pois o pai e o irmão trabalhavam fora. Aprendera a fazer artesanato. Buscava argila nas margens do rio próximo à sua casa e ambas, mãe e filha, produziam panelas, potes e outros utensílios de barro que eram vendidos na vila. Elas não reclamavam a ausências dos homens, naquele tempo Ponciá "não guardava ainda muitas tristezas no peito" (EVARISTO, 2003, p.18).

Como o romance narra os caminhos e os descaminhos da personagem, sua jornada inicia quando Ponciá começa a perceber as amarras sociais que a prendiam a uma vida marcada pela miséria, pelas condições desumanas de subsistência e pela exploração material e psicológica que acompanhavam todas as gerações das famílias que viviam na vila. Então, a moça decide sair da roça e buscar novas oportunidades na cidade grande. Trecho este interessante visto que a moça utiliza como meio de transporte o trem, um dos papéis que coube a esse meio de transporte no romance foi o de substituir o navio negreiro em tempos modernos. É através dele que acontece a diáspora de toda família de Ponciá - um a um foram saído da roça em direção ao grande centro.

$\mathrm{Na}$ cidade grande ela descobre uma nova forma de opressão, torna-se prisioneira de sua etnia e de sua condição feminina. Rápido a cidade a absorve, ser alfabetizada não foi suficiente para conseguir um bom emprego; segue o "destino" das mulheres negras dos grandes centros, torna-se empregada doméstica. Consegue juntar dinheiro e compra um barraco na periferia da cidade, onde passa a morar com o marido. Este aparece no texto identificado apenas como "o homem de Ponciá" e não por um nome. Ele trabalha na construção civil e também é vítima do sistema excludente, e se vê perdido e abandonado pela sociedade, repassando a violência que recebe das ruas diretamente em casa:

O homem de Ponciá estava cansado. Sua roupa empoeirada, assim como seu corpo, porejava pó. (...) Ao ver a mulher tão alheia, teve desejos de trazê-la ao mundo à força. Deu-lhe um violento soco nas costas, gritando-lhe pelo nome (EVARISTO, 2003, p.17).

Na cidade, Ponciá, passava por privações muito diferentes daquelas vividas na roça; ali vivia em condições subumanas, semelhantes às dos seus ancestrais trazidos da África:

O pó avolumava-se por cima do armário velho. Pelos caibros do telhado acumulavam-se teias de aranhas e picumãs. As trouxas de roupas sujas cresciam dias e dias pelos cantinhos do quarto. As folhas 


\section{das Letras}

de jornal, que forravam prateleiras do armário, já estavam amareladas pelo tempo e roídas nas pontas pelos ratos e baratas (EVARISTO, 2003, p.22).

O mundo externo ao da vila lhe proporcionou um grande desgosto, seus sonhos foram morrendo aos poucos; aparentemente, Ponciá foi se acomodando a uma vida de sofrimentos, mas como já multiplicava muitas perdas e lutava para romper com seu destino imanente, questionava sua nova condição de vida e incomodava com a abnegação do marido: “(...) Deus meu, será que o homem não desejava mais nada? Para ele bastava o barraco, a comida posta na lata de goiabada vazia?" (EVARISTO, 2003, p.43).

Evaristo é consciente, cede espaço também aos homens, igualmente objetos da opressão. Emudecidos pelas faltas e pelas perdas. De uma maneira geral, todos sofriam de banzo. O avô de Ponciá emudeceu diante dos sofrimentos do cativeiro, o pai de Ponciá era quase mudo diante da servidão no campo; o irmão de Ponciá acompanhava o pai, mas ainda cantava e o homem de Ponciá ia emudecendo diante da realidade nua e crua do cotidiano, ia emudecendo diante das perdas dos filhos, ia emudecendo diante da fome. Fome de vida, inclusive.

Esse olhar voltado para os personagens masculinos reforçam o cuidado da escritora em apontar as mazelas que atinge o ser humano em sentido amplo, e que vão ganhando diferentes pesos na medida em que elementos ligados ao gênero, à etnia e a classe social são acrescentados e particularizando o sofrimento.

Por diversas vezes o marido de Ponciá se mostrou também um sofredor, contudo ele extravasava suas angústias tratando a esposa com violência, conforme o trecho a seguir:

Um dia ele chegou cansado, a garganta ardendo por um gole de pinga e sem um centavo para realizar tão pouco desejo. Quando viu Ponciá parada, alheia, morta-viva, longe de tudo, precisou fazê-la doer também e começou a agredi-la. Batia-lhe, chutava-lhe, puxava-lhes os cabelos. Ela não tinha um gesto de defesa. (EVARISTO, 2003, p. 98).

O homem controlado por pressões extremas pode realizar um movimento, que segundo a pesquisadora Cida Salgueiro: "intercala sua postura de dominado com outra de dominador, buscando a presa mais próxima para a inversão de sua conduta: a mulher e a família que tem a seu lado." (SALGUEIRO, 2004, p.54).

Desse modo, podemos inferir que os homens nesse romance são, ao mesmo, tempo algozes e vítimas de si mesmos em virtude de suas condições étnicas e socioeconômicas. A rotina do marido de Ponciá Vicêncio ilustra bem os argumentos acima e reforçam o teor do sofrimento que o atinge levando-o ao ápice da violência contra a mulher:

Um dia ele chegou cansado, a garganta ardendo por um gole de pinga e sem um centavo para realizar tão pouco desejo. Quando viu Ponciá parada, alheia, morta-viva, longe de tudo, precisou fazê-la doer também e começou a agredi-la. Batia-lhe, chutava-lhe, puxava-lhes os cabelos. Ela não tinha um gesto de defesa. (EVARISTO, 2003 p. 98).

O que fica evidente na sequencia das brutalidades aplicadas contra Ponciá é que esses atos de violência se tornaram vias de mão dupla para com seu Homem, pois ele a sentia também como 


\section{das Letras}

uma espécie de autoflagelação. No fundo o marido a culpava por seu próprio fracasso, por não conseguir entrar no mundo da mulher e alcançá-la:

Quando o homem viu o sangue a escorrer-lhe pela boca e pelas narinas, pensou em matá-la, mas caiu em si assustado. Foi ao pote, buscou uma caneca d'água e limpou arrependido e carinhoso o rosto da mulher. Ela não reagia, não se manifestava qualquer sentimento de dor ou de raiva. (...) Ele ficou com o remorso guardado no peito. (EVARISTO,2003, p. 98-99).

Assim, emparedados na mudez os homens em Ponciá Vicêncio eram também subjugados pelas circunstâncias; do pai de Ponciá, por exemplo, só se escutava um grunhido: "hum, hum, hum... foi naquela época que Ponciá começou a achar que homem era quase mudo. Seu irmão falava, mas parece que estava ficando mudo também." (EVARISTO, 2003, p. 56). O mesmo comportamento é observado no marido da protagonista:

Ponciá Vicêncio achava que os homens falavam pouco. (...). Agora, aquele, o dela, ali calado, confirmava tudo. Ele também só falava o necessário. Só que o necessário dele era bem pouco, bem menos do que a precisão dela. (...). Quantas vezes quis ouvir, por exemplo, se o dia dele tinha sido difícil, (...). Quis que o homem lhe falasse dos sonhos, dos planos, das esperanças que ele depositava na vida. Mas ele era quase mudo. Não chorava, não ria. (EVARISTO,2003, p. 67).

No entanto, tais justificativas não isentam o homem de assumir uma conduta, orientada por valores tradicionais e patriarcais, que condiciona a mulher a novas formas de violência e opressão; pelo contrário, espera-se uma mudança significativa e positiva em seu comportamento, quando ele percebe que seu status passa de dominado a dominador dependendo do lugar onde se encontra.

No romance Ponciá Vicêncio, Evaristo realiza uma escrita atravessada pelo espectro da melancolia e da depressão. Para Sigmund Freud:

a melancolia se apresenta como um desânimo profundamente penoso, há uma cessação de interesse pelo mundo externo, perda da capacidade de amar, há inibição de toda e qualquer atividade, e uma diminuição dos sentimentos de auto-estima a ponto de encontrar expressão em auto-recriminação e auto-envilecimento, culminando numa expectativa delirante de punição. (FREUD, p.250).

Julia Kristeva em Sol Negro: depressão e melancolia (1989) escreve que o homem melancólico vive num espaço imaginário, em que o passado não passa. $O$ sujeito vive assombrado por uma tristeza inconsolável, sente a perda insubstituível que o aproxima do desespero, é “... um abismo de tristeza, dor incomunicável que às vezes nos absorve, em geral de forma duradoura, até nos fazer perder o gosto por qualquer palavra, qualquer ato, o próprio gosto pela vida.” (KRISTEVA, 1989, p. 11):

Ela [Ponciá] ficou durante uns momentos longe, vazia, com o olhar parado, sussurrando coisas incompreensíveis. Ele [marido] quis tocar nela, perguntar, sacudir, mas teve medo, muito medo de abeirar-se de um vazio que era só dela (EVARISTO, 2003, p. 65, grifo nosso). 
Kristeva também associa o estado depressivo a uma fragmentação do ego (pulsão de morte), que, por sua vez, conduz a uma fragmentação da fala do sujeito: "Lembre-se da palavra do deprimido: repetitiva e monótona. Na impossibilidade de encadear, a frase se interrompe, esgota-se, pára.” (KRISTEVA, 1989, p.39). O discurso do depressivo destaca Kristeva, é desprovido de encadeamento lógico: “o depressivo, (...), preso à sua dor, não encadeia mais e, por conseguinte, não age, nem fala”. (Idem, p. 39-40).

O homem de Ponciá acabava de entrar em casa e viu a mulher distraída na janela. Olhou para ela com ódio. A mulher parecia lerda. Gastava horas e horas ali quieta olhando e vendo o nada. Falava pouco e quando falava, às vezes dizia coisa que ele não entendia (...). Uma noite ela passou todo o tempo diante do espelho chamando por ela mesma. Chamava, chamava e não respondia. Ele teve medo, muito medo (EVARISTO, 2003, p.16-17).

O romance Ponciá Vicêncio, no decorrer da narrativa, escancara a exclusão por que passam uma imensa parte da população brasileira. Dados do IBGE de 2017 indicam que no Brasil são cerca 14,08 milhões as pessoas em situação de extrema pobreza. Isso corresponde a $11 \%$ da população. Pessoas que saíram das zonas rurais ou de outros meios urbanos enxergam nos grandes centros possibilidades de uma vida melhor. O resultado são periferias imensas, sem saneamento, com esgoto fazendo ilhas nos quarteirões, com pessoas morando em barracos de madeira, folha de zinco ou papelão às margens de rios transformados em canais, mesmo que ganhem cem reais por mês, estão na miséria.

Vale lembrar que a população que ocupa as periferias das grandes cidades não é formada apenas por negros. Entretanto, como qualquer grupo menor os negros brigam por espaços no meio social. Espaços que podem se transformar em lugares de referências de ritos, simbologias, ancestralidade, costumes e valores. Para tanto precisam lutar e negar os lugares que lhes são "naturalmente reservados" - tais como os cortiços, as favelas, os morros e qualquer outro espaço urbano traduzido em segregação socioespacial.

Por mais que os órgãos públicos e serviços sociais criem ações positivas propondo mudanças de comportamento na sociedade, o negro brasileiro ainda carrega o estigma de sempre ocupar a margem; substituir o termo 'favela' por 'comunidade' a fim de elevar a alto-estima dos sujeitos não os liberta dos grilhões da discriminação, pelo contrário, reforça a ideia de "lugar natural" desenvolvida por Aristóteles e recuperada pela antropóloga Lélia Gonzáles em artigo de 1982.

Nos anos de 1980, com o advento do lançamento dos Cadernos Negros publicados em 1978, muitos militantes da causa negra ganharam força no cenário político e artístico brasileiro. Uma das grandes vozes que se fizeram ouvir foi de Lélia Gonzalez. Com formação em antropologia, Gonzalez tinha como principal preocupação a condição de vida dos excluídos. Como professora de ensino médio fez de suas aulas espaço de resistência e crítica político-social. Seus escritos e palestras, atuando contra o racismo e outras formas de discriminação, contribuíram para a formação acadêmica e cidadã de muitos dos que com ela conviveram. Em 1982 Gonzalez publicou em parceria com o sociólogo Carlos Hasenbalg o livro Lugar de Negro. Neste, está inserido o artigo O movimento negro na última década, em que a antropóloga apresenta, de forma ainda binária, uma análise 
sobre a desigualdade racial no Brasil e indica o lugar social e espacial de negros e brancos, para isso Gonzalez se apropriou da ideia aristotélica de lugar natural:

As condições de existência material desta população negra remetem a condicionamentos psicológicos
que têm que ser atacados e desmascarados. Os diferentes modos de dominação das diferentes formas
de produção econômica existentes no Brasil parecem coincidir num mesmo ponto: a reinterpretação
da teoria do "lugar natural" de Aristóteles. Desde a época colonial aos dias de hoje, a gente saca a
existência de uma evidente separação quanto ao espaço físico ocupado por dominadores e dominados.
O lugar natural do grupo branco dominante são moradias saudáveis, situadas nos mais belos recantos
da cidade ou do campo e devidamente protegidas por diferentes formas de policiamento que vão desde
os feitores, capitães do mato, capangas, etc., até a polícia formalmente constituída. Desde a casa grande
e do sobrado até os belos edifícios e residências atuais, o critério tem sido o mesmo. Já o lugar natural
no negro é o oposto, evidentemente: da senzala às favelas, cortiços, invasões, alagados e conjuntos
"habitacionais" (...) dos dias de hoje, o critério tem sido simetricamente o mesmo: a divisão racial do
espaço. (GONZALEZ, 1982, p. 15)

Embora o artigo de Lélia Gonzalez realize a leitura de uma sociedade brasileira da segunda metade do século XX, a divisão racial do espaço se mantém nos dias atuais, até porque há uma insistente tentativa de estabelecer algum tipo de vínculo entre os moradores e tais lugares que possa validar sua permanência nele.

Pode-se lembrar ainda, das palavras de Stuart Hall (2006) ao concluir que todas as identidades estão localizadas em um tempo e em um espaço simbólicos e que elas possuem o que Edward Said (2003) chama de "geografias imaginárias", ou melhor, elas possuem suas paisagens características, seu senso de lugar, bem como localizações no tempo, nas tradições - ainda que inventadas - que ligam o passado ao presente; neste caso, o lugar que o negro ocupa não oferece boas memórias ou perspectivas futuras. Lélia Gonzalez conclui, no artigo supracitado, que existe um lugar de negro, e é aquele constituído pela segregação que ela reconhece como lugares invisíveis aos olhos das autoridades e fora do alcance dos serviços sociais.

O romance Ponciá Vicêncio abre possibilidades para várias leituras e análises em diversas ciências, as questões sobre a fome e as outras mazelas sociais que desembocam no estado da depressão são insistentes em toda narrativa. Entretanto, as polêmicas geradas no campo literário, desafiam a máxima canônica de que a escrita afrobrasileira está restrita apenas à poesia ou ao conto, como uma extensão da oralidade.

\section{CONSIDERAÇÕES FINAIS}

No romance Ponciá Vicêncio, Evaristo expressa na arte de escrever sua herança de contadora de histórias e nesse traço retorna à sua ancestralidade que aparece forte em suas narrativas. Através dessa escrita rica em simbolismo e poesia, a autora nos conta um pouco de si, de sua vivência, de suas lembranças, nos fala de suas estratégias de resistência diante de uma sociedade, que ainda valoriza o que é produzido pelo homem branco. 
A autora costuma dizer em entrevistas que "não nasceu cercada por livros, mas cercada por palavras", revelando sua herança afro-mineira de contar histórias. Conceição também bebeu de suas fontes culturais e históricas, para construir seu mundo de contos e de causos que mescla ficção com não-ficção, memória individual e coletiva.

O romance Ponciá Vicêncio é repleto de elementos do cotidiano, que são simples, mas expostos com tanta poesia que se tornam ricos de significados outros. Ao dar vida a um sujeito marcado pela dor, tocado pela condição de ser mulher e negra num país que a faz uma vítima natural, Conceição Evaristo permite, com firmeza, que esse sujeito desvele o fosso social que separa a sociedade entre os que têm possibilidades e os que não têm nem esperança de vir a ter.

Com sua escrita Evaristo procura fazer sua parte enquanto cidadã, pois já ocupa um lugar privilegiado na sociedade e procura desmitificar o que o senso comum apregoa: de que a população negra é mais pobre por falta de instrução, garra e determinação.

Embora a assertiva de que "a favela é a senzala da contemporaneidade" já esteja se tornando clichê, ainda dá tempo de dizer que não basta apenas responsabilizar o poder público para mudar essa realidade. Por intermédio dos dramas vividos pelos personagens de Ponciá Vicêncio, Evaristo chama atenção para as feridas abertas para além do corpo físico dos sujeitos negros subalternizados.

A literatura é capaz de tornar o sujeito leitor mais crítico e empoderado, no caso específico da literatura afrobrasileira, permite a compreensão de que no Brasil, o negro não é discriminado apenas pela cor da pele, mas também pela condição socioeconômica. Desse modo, as mazelas descritas em Ponciá, ganham outros sentidos, isto é, a fome não se restringe à necessidade do alimento para o corpo, mas se aproxima daquilo que agride a alma e não se descreve com palavras. Há mais que tristeza em Ponciá Vicêncio, há ecos de um passado próximo que muitos de nós e o poder público ainda insiste em não ouvir.

\section{REFERÊNCIAS}

DUARTE, Eduardo de Assis. Literatura e afrodescendência no Brasil: antologia crítica. Belo Horizonte: Editora UFMG, 2011. 4v.

EVARISTO, Conceição. Ponciá Vicêncio. Belo Horizonte: Mazza, 2003.

FREUD, S. Luto e Melancolia. Edição Standard Brasileira das Obras Completas de Sigmund Freud, vol. XIV, Imago, Rio de Janeiro, 1914-1916.

HALL, Stuart. A identidade cultural na pós-modernidade. Trad. Tomaz Tadeu da Silva e Guacira Lopes Louro. 5. ed. Rio de Janeiro: DP\&A Editora, 2001.

IBGE - Instituto Brasileiro de Geografia e Estatística | Portal do IBGE. Disponível em:< https:// wmw.ibge.gov.br/>. Acesso em 15 jul.2018.

JESUS, Carolina Maria de. Quarto de Despejo: diário de uma favelada. 9. ed. São Paulo: Edição Popular, 1960. 
KRISTEVA, Julia. Sol Negro: Depressão e Melancolia. Rio de Janeiro: Rocco, 1989.

ONU - Organizações das Nações Usinas. História | ONU Brasil. Disponível em: <https:// nacoesunidas.org/conbeca/ historia/ >. Acesso em: 15 jul.2018.

SALGUEIRO, Maria Aparecida Andrade. Escritoras negras contemporaneas: estudos de narrativas: Estados Unidos e Brasil. Rio de Janeiro: Caetés, 2004.

SAID, Edward. Reflexões sobre o exílio e outros ensaios. Trad. Pedro Maia Soares. São Paulo: Companhia das Letras, 2003.

Recebido em: 05/05/2018

Aprovado em: 20/09/2018

Publicado em: 01/12/2018 